\title{
DOES ORGANIZATIONAL JUSTICE INCREASE OR DECREASE ORGANIZATIONAL DISSENT?
}

\author{
DOI: 10.17261/Pressacademia.2019.1017 \\ RJBM- V.6-ISS.1-2019(1)-p.1-8 \\ Mehtap Ozsahin ${ }^{1}$, Senay Yurur ${ }^{2}$ \\ ${ }^{1}$ Yalova University, Department of Management, 77200, Yalova, Turkey. \\ mehtap.ozsahin@yalova.edu.tr, ORCID: 0000-0003-2527-4166 \\ ${ }^{2}$ Yalova University, Department of Management, 77200, Yalova, Turkey. \\ senay.yurur@yalova.edu.tr, ORCID: 0000-0002-3859-9827
}

To cite this document

Ozsahin, M., Yurur, S. (2019). Does organizational justice increase or decrease organizational dissent?. Research Journal of Business and Management (RJBM), V.6(1), p.1-8.

Permemant link to this document: http://doi.org/10.17261/Pressacademia.2019.1017

Copyright: Published by PressAcademia and limited licenced re-use rights only.

\begin{abstract}
Purpose - This study aims to examine the effect of organizational justice on organizational dissent.

Methodology- A quantitative research is conducted on white and blue color employees of large scale and medium sized firms operating in automotive industry in Bursa-Turkey. 105 employees, thorough face-to-face survey administration, filled out questionnaire forms. Convenience sampling method is used. Data obtained from those 105 questionnaires were analyzed through the SPSS statistical packet program.

Findings - Research findings revealed the positive effects of procedural and distributive justice on upward organizational dissent, whilst the nonsignificant relation between interactional justice and upward organizational dissent. Analyses results also indicated the non-significant relations of procedural, distributive and interactional justice to latent organizational dissent.

Conclusion - The finding of positive effect of procedural justice and distributive justice on dissent behavior, is consistent with the literature, which indicates that justice perceptions of managerial employees increased upward dissent behaviors. However, the finding of this research implying a non-significant effect of interactional justice on organizational justice is inconsistent with the literature, which indicates employees getting better relationship with their managers are more prone to upward dissent. In scope of this survey, employees' dissent behaviors are influenced by fairness of formal rules and procedures, and acquisitions rather than the fairness of managerial relationships. This distinctive result of this survey may stem from employees' distrust in relationship with their managers and their prioritization of formal procedures and concrete acquisitions rather than abstract relationships while evaluating the possible retaliations and results of their dissent.
\end{abstract}

Keywords: Organizational justice, distributive justice, procedural justice, interactional justice, organizational dissent.

JEL Codes: M12, M14, M19

\section{INTRODUCTION}

The questions of "Are employees, who perceive they are treated fair in their organizations, are more prone to opposition or more prone to accept decision and not having need to dissent? Does organizational justice perception affect the organizational dissent? If yes, how does it affect the organizational dissent, does organizational dissent increases organizational justice or not?" has motivated researchers to search the relationship between organizational justice and organizational dissent, so to initiate this study.

Researches on organization justice found out that organizational justice shapes employees' behaviors which result in positive or negative outputs for organization. Organization citizenship behavior (Lavelle et al., 2009), organizational commitment (CohenCharash and Spector, 2001), job satisfaction (Yürür, 2008) and performance (Zapata-Phelan et al., 2009), are considered as some positive outputs of organization justice, while theft (Greenberg, 1990a), retaliation behaviors (Skarlicki and Folger, 1997) and counterproductive behaviors (Fox, et al., 2001) are classified as some negative outputs of organizational injustice. 
So, organizational justice perception shaping many attitudes and behaviors of employees, is expected to affect internal dissent in organization. Organization dissent, being defined as expressing disagreement or contradictory opinion in workplace (Kassing, 1998), has been focused on while examining employees' attitudes and behaviors, as like work engagement (Kassing et al., 2012), whistleblowing (Kassing, 1998), employees' aggressiveness (Kassing and Avtgis, 1999), employees' justice perception (Kassing and McDowell, 2008).

Kassing (1997) proposed an organizational dissent model including multistep process: (1) feeling apart from one's organization (dissent experiment) and expressing disagreement and contradictory opinions about one's organization (dissent expression) (1998:183). He argues that employees' dissent expression time and expression way will wary depending organizational, relational and individual influences (1997). Individual influences consist of employees' personal and demographic characteristics, their attachment to or affinity for their organizations, while relational influences are about the type and nature of relationships employees possess within organizations. Organizational influences also refers to organizational culture, structure and climates which foster or impede dissent (2011:1378-1379). This paper examining the effect of organizational justice on organization dissent will handle organizational justice in the context of the organizational influences.

Moreover, Kassing ve Armstrong (2002) indicated unfair practices in organization as triggers of organizational dissent. Namely, injustice is accepted as an initiative factor that stimulates dissent behavior in organization. However justice is also accepted as enhancer factor that increase organizational dissent in workplace (Kassing ve McDowell, 2008). In other words, organizational dissent behaviors come out of unfair practices and keep going through fair climate in organization. In a fair climate in organization, individual trusts in his/her organization, and prefers to dissent in decision making process without any fear rather than to keep silent. While organizational injustice is an initiative factor of organization dissent in beginning, it becomes undesirable factor subsequently in order organization dissent to be kept on. So, this noteworthy relationship between organizational justice and organizational dissent still needs to be explained in detailed. In this context, this survey, being conducted in Turkey-a developing country having different cultural context and examining the effects of organizational justice dimensions on organizational dissent types in detailed, is expected to fill out a gap and contribute to literature.

In this respect, this study consists of five sections. After a general information about the study is provided in introduction part; the constructs of organizational justice and organizational dissent, and the relationships among those constructs will be explicated in the second section. Detailed information about the survey (such as sample characteristics, measure sources, analyses etc.) and findings of the survey will be submitted in the third and fourth sections of the study respectively. Lastly, the findings will be discussed and the comments about primary results of this survey will be given in the last section.

\section{LITERATURE REVIEW}

Organizational dissent is defined as employees' expression of their disagreements and contradictory opinions about workplace policies and practices to various audiences (Kassing, 2011). Based on the type of audience, Kassing $(1997,1998,2011)$ classified the organization dissent into three groups. Upward or articulated dissent, in which employees express their disagreements and contradictory opinions in workplace to their directors directly, while in lateral dissent they prefer their co-worker to express their dissent. In both of organization dissent type, audience are internal audience working in organization. However, in third type of organizational dissent, called as displaced dissent, employees can share their contradiction and disagreements about their work place with external audiences as like their family members and friends (Kassing, 1997, 1998, 2011). Indeed Kassing (2000) classified both lateral and displaced dissent into one group, named as latent dissent, because both dissent types include the dissent to the entities (co-workers and family members) who don't have power to make job related decisions. Thus, actually two types of organizational dissent can be referred: upward (articulated) dissent, to executives who have decision making authority and latent dissent, to any audience who does not have decision making authority. Previously Graham (1986) also classified organizational dissent in terms of content of dissent as personal advantage dissent (eg. dissent about work hours cut or extra duty performing) and principled dissent (eg. dissent about unethical or questionable practices). While Graham's classification is more related to individual's moral values, Kassing's classification concerns with audience, which is mostly affected by individual, relational and organization influences (Kassing, 1997). In this context, organizational justice, as a part of organizational influences, is expected to affect organization dissent types in terms of audience. More understandably, in accordance with perceived organizational justice, employees' audience preference to express their dissent will change.

Organizational justice literature reveals three types of justice: distributive justice, procedural justice and interactional justice (Masterson et al., 2000). Distributive justice refers to the "employees' fairness perception about the distribution of outcomes" (Greenberg, 1990), while procedural justice refers to the "perceived fairness of the processes that lead to those outcomes" (Leventhal, 1980). Interactional, the most recently recognized form of justice, refers to the "interpersonal treatment people receive as procedures are enacted", and is more related to the quality of the relationship between the supervisor and the 
subordinate (Bies \& Moag, 1986). Greenberg (1993) suggested a four-factor structure for organizational justice by repositioning interactional justice as two separate dimensions- interpersonal and informational. Four-factor view of justice was tested and justified empirically for the first time by Colquitt's survey in 2001. Informational justice was conceptualized as the fairness of explanations and information provided to the people who are influenced by distribution decisions, while interpersonal justice was defined as fairness of interpersonal treatment provided during the enactment of procedures and distributions of outcomes (Greenberg, 1993).

Scholars investigated positive relation of perceived fairness to job satisfaction (Clay-Warner, Reynolds, \& Roman, 2005; Schappe, 1998), organizational citizenship behavior (Moorman, 1991), and organizational trust (Hubbell \&Chory-Assad, 2005) of employees. Additionally, perceived fairness affects the way people communicate within organizations and leads them to behave in a cooperative manner (Rahim, Magner, \& Shapiro, 2000). As can be seen in literature, increase in perceived organizational justice frequently produces positive outcomes for organization. So, organizational justice, referring to the perceived fairness of employees on organizational procedures, practices and directors in workplace (Folger and Cropanzano, 1998), can be considered as an essential antecedent of employees' dissent behaviors. Social exchange theory of Blau (1965) constitutes a base to explain this relationship between organizational justice and organizational dissent behavior. According to the theory, individuals have two type of exchange relation to their employers and organizations. One type is economic exchange, in which individual receive some economic outputs in exchange of his/her contribution to organization. The second type is social exchange, in which individual would like to contribute to organization in exchange of her/his social acquisitions. Previous researches demonstrated that organizational justice is an organizational inducement in return employees are willing to contribute to organization (Moorman, 1991; Konovsky ve Pugh, 1994; Masterson, vd., 2000; Rupp ve Cropanzano, 2002; Cropanzano, Prehar ve Chen, 2002; Colquitt, vd. 2012). Kassing and McDowell, (2008) proposed that organizational justice affect employees' dissent behaviors. Accordingly, employees with high level of justice perception, prefer upward dissent (internal audience, specifically directors to express dissent), which is more beneficial for organization rather than displaced dissent (external audience to express dissent) (Kassing and McDowell, 2008). So, to describe in terms of social exchange terminology, when employee perceives fairness, which can be included in inducements provided by organization, s/he prefers the upward dissent, namely would like to contribute to organization positively.

Some researchers have argued that how fair employees perceive their organizations has a clear impact on how they express dissent (Goodboy, Chory, \& Dunleavy, 2009; Kassing \& McDowell, 2008). For example, Kassing (2000) indicated that employees who think getting good relationship to their executives are more prone to upward dissent. When employees communicate and express their contradictory opinions to their executives without any hesitation, latent dissent (to co-workers) and displaced dissent (to external entities as like family members) will disappear. Additionally, employees having perception of fairness about decisions and decision making process, will not need latent or displaced dissent resistance to those decisions (Kassing and McDowell, 2008).

Even though previous researches revealed the relationship between organizational justice and organizational dissent empirically (Kassing and McDowell, 2008), how organizational justice types shape the organizational dissent behavior still need to be highlighted. In this context, Goodboy, Chory and Dunleavy (2008), investigated that the distributive and interpersonal justice decreased latent dissent. Same research also indicated a non-significant effect of organizational justice types on upward and displaced dissent (Goodboy et al., 2008). However, literature on employee voice and whistle blowing, which are commonly considered to be synonymous with dissent, has indicated that perceived organizational injustice increased the organizational silent (Pinder and Harlos, 2001; Tangirala ve Ramanujam, 2008; Siefert vd., 2010; Miceli vd., 2012). Namely, injustice in organization discourages employees to speak out. Especially if employees have contradictory options about decisions, in an unfair organization, they prefer to keep on silent with the fear of being injured in future.

In the light of previous researches, it can be argued that organizational justice will increase upward or articulated dissent while decrease latent dissent. As indicated at literature review part, Kassing (2000) proposed two types of organizational dissent upon to types of audience. The expression of dissent to internal audience who have decision making power refers to upward (articulated) dissent, while the expression of dissent to external or internal audience who don't have decision making authority refers to latent dissent. So displaced dissent to unauthorized-external audience and lateral dissent to unauthorized-internal audience can be embodied in one dimension because both of them are expressed to unauthorized audience, which constitutes the common characteristic of them. Thus, this research focused on upward and latent dissent, on which the effects of distributive, procedural and interactional justice have been searched. So, consisting of three organizational justice dimensions and two dissent dimensions, the following hypotheses are proposed and research model is shaped: 
H1a. Procedural justice perception of employees increases the upward dissent.

H1b. Distributive justice perception of employees increases the upward dissent.

H1c. Interactional justice perception of employees increases the upward dissent.

$\mathrm{H} 2 \mathrm{a}$. Procedural justice perception of employees decreases the latent dissent.

$\mathrm{H} 2 \mathrm{~b}$. Distributive justice perception of employees decreases the latent dissent.

H2c. Interactional justice perception of employees decreases the latent dissent.

Figure 1: Research Model

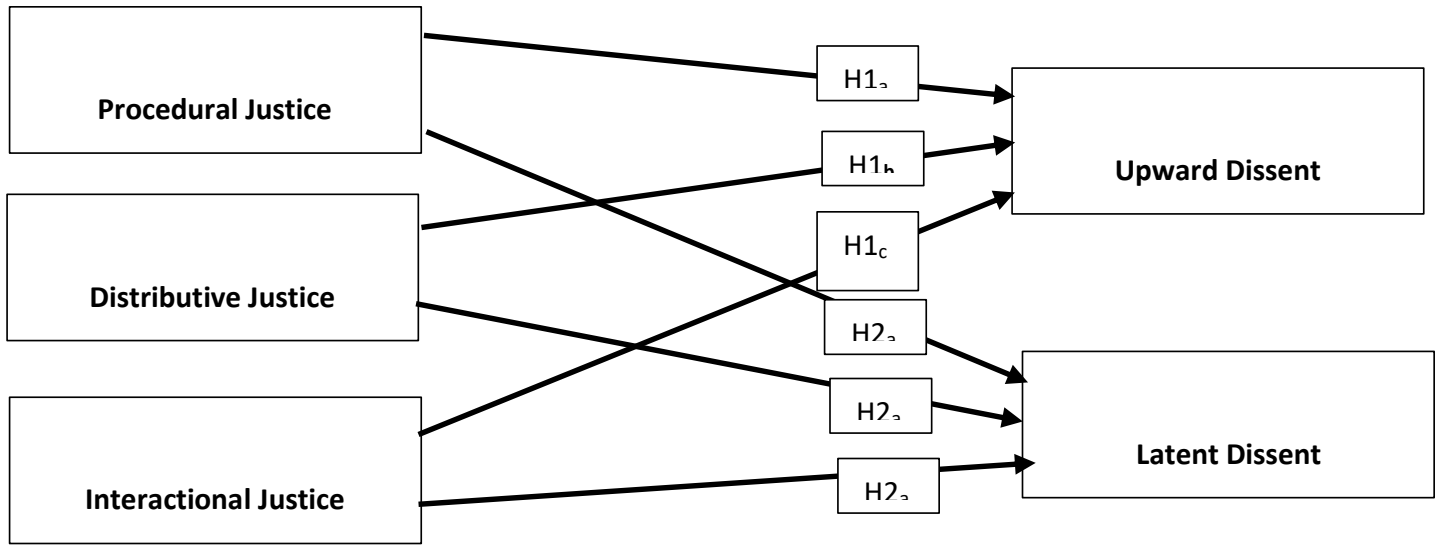

\section{DATA AND METHODOLOGY}

\subsection{Sample}

The survey is conducted 105 white and blue color employees of large scale and medium sized firms operating in automotive industry in Bursa-Turkey. Questionnaire forms were filled out by employees, thorough face-to-face survey administration. Convenience sampling method is used. Data obtained from those 105 questionnaires were analyzed through the SPSS statistical packet program.

Of the 105 participants, $69 \%$ are male, $31 \%$ female; \%57,1 married while \%42,9 are single. Most of the participants (63,8 \%) are included in 31-40 years-old interval. Employees participating in the survey mostly have higher education level $(64,8 \%$ are university graduate; $23 \%$ have post graduate degree) (all sentences 9 punto, calibri, single space)

\subsection{Measures}

Researchers benefited from the previous scales frequently used in literature to form the measurement instruments of the questionnaire. In this regard, a multidimensional scale of organizational justice based on the measurement instrument of the best known study of Jason A. Colquitt in 2001. The measurement instrument of organizational justice consists of 20 items based on three dimensions - procedural justice (7 items), distributive justice (4 items), interactional justice (9 items). To measure organizational dissent, 15 items-scale adopted from study Kassing (2000) was used. Organizational dissent scale includes two dimension; upward dissent with 8 items and latent dissent with 7 items. Scales used to measure constructs in this study had been translated in to Turkish previously and used at surveys conducted in Turkey (organizational justice scale by Yürür and Demir, 2011; organizational dissent scale by Dağlı, 2015). Overall, 35 items measuring organizational justice and organizational dissent were assessed with five-point-Likert Type scale with anchors $1=$ strongly disagree and 5=strongly agree.

Cronbach's alpha values ranging from 0.784 to 0.947 (Cronbach's $\alpha$ values for Upward dissent with 8 item 0.784 ; latent dissent with 7 items 0.784; procedural justice with 7 items 0.802 ; distributive justice with 4 items 0.921 ; interactional justice with 9 items 0.947 ) for each constructs indicates reliability of scales. 


\section{FINDINGS}

To test hypotheses, researchers employed multiple regression analyses which incorporates three independent variablesprocedural justice, distributive justice, interactional justice-, and two depended variables-latent dissent and upward dissent.

Table 1: Regression Analyses Results

\begin{tabular}{|c|c|c|c|c|c|c|c|}
\hline $\begin{array}{l}\text { Regression } \\
\text { Model }\end{array}$ & $\begin{array}{l}\text { Independent } \\
\text { Variable }\end{array}$ & $\begin{array}{l}\text { Depended } \\
\text { Variable }\end{array}$ & Standardized $\beta$ & Sig. & $\begin{array}{c}\text { Adjusted } \\
\text { R2 } \\
\end{array}$ & $\begin{array}{c}\mathbf{F} \\
\text { Value }\end{array}$ & $\begin{array}{c}\text { Model } \\
\text { Sig. }\end{array}$ \\
\hline \multirow{3}{*}{ Model 1} & Procedural Justice & \multirow{3}{*}{$\begin{array}{l}\text { Upward } \\
\text { Dissent }\end{array}$} & $0,327 * * *$ & 0,001 & \multirow{3}{*}{0,453} & \multirow{3}{*}{29,657} & \multirow{3}{*}{0,000} \\
\hline & Distributive Justice & & $0,478 * * *$ & 0,000 & & & \\
\hline & Interactional Justice & & 0,053 & 0,552 & & & \\
\hline \multirow{3}{*}{ Model 2} & Procedural Justice & \multirow{3}{*}{ Latent Dissent } & $-0,040$ & 0,697 & \multirow{3}{*}{0,340} & \multirow{3}{*}{18,898} & \multirow{3}{*}{0,000} \\
\hline & Distributive Justice & & $0,588 * * *$ & 0,000 & & & \\
\hline & Interactional Justice & & $-0,149$ & 0,126 & & & \\
\hline
\end{tabular}

As been depicted on Table 1 , findings indicate significant relations of procedural justice $(\beta=0,327 ; p \leq, 001)$ and distributive justice $(\beta=0,478 ; p<, 001)$ to upward dissent. So $\mathrm{H} 1 \mathrm{a}$ and $\mathrm{H} 1 \mathrm{~b}$ implying that procedural justice and distributive justice respectively increase upward dissent have been accepted. However, $\mathrm{H} 1 \mathrm{c}$ stating that interactional justice increase the upward dissent in organization has not been supported $(\beta=0,053 ; p=, 552)$.

The analysis results for Model 2 also revealed a positive significant relation of distributive justice to latent dissent $(\beta=0,588$; $p<, 001)$, even though research hypothesis proposed a negative relationship between distributive justice and latent dissent. Moreover, analyses results revealed non-significant relations of procedural and interactional justice to latent dissent $(\beta=-0,040$; $p=, 697$ for procedural justice and $\beta=-0,149 ; p=, 126$ for interactional justice). So, none of the hypotheses (H2a, H2b, H2c) indicating negative relationships between organizational justice types and latent dissent are supported.

The findings of research analyses are demonstrated below in the research model:

Figure 2: Final Research Model

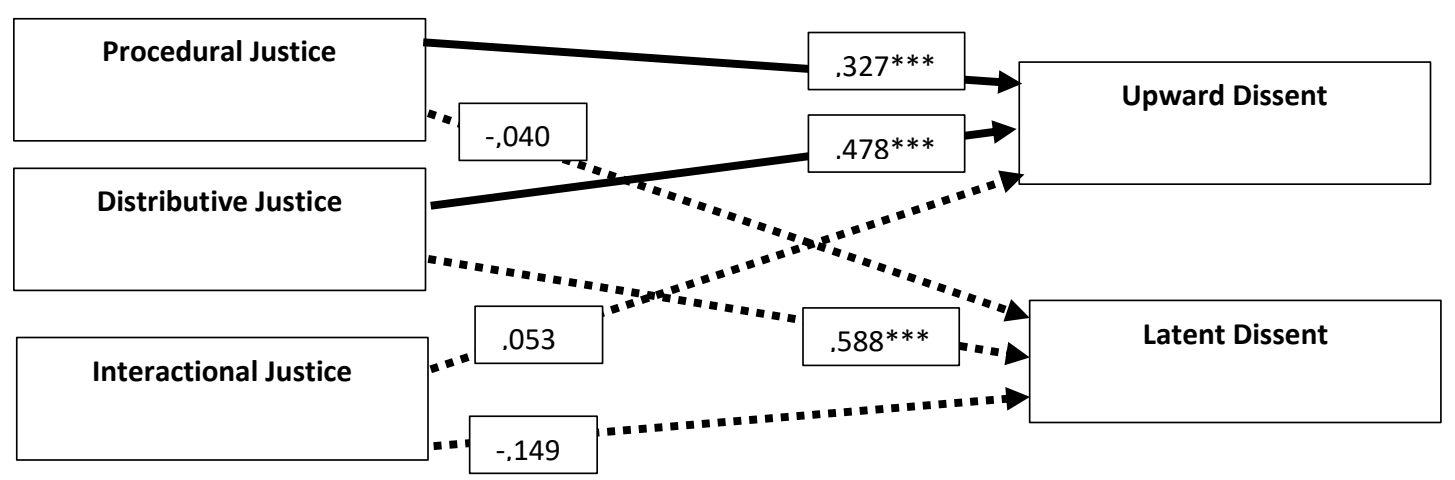




\section{CONCLUSION AND DISCUSSIONS}

The main objective of this research is to analyze the effects of organizational justice perceptions of employees on their dissent behavior. In relevant literature, organizational injustice is considered paradoxically as both triggering factor that initiates the dissent (Kassing and Armstrong, 2002) and suppressive factor that impede to evolve the dissent in organization (Kassing and McDowell, 2008). Actually, the relationship between organizational justice and organizational dissent is non-linear. While injustice initiates organizational dissent in organizations, organizational dissent needs justice in order to evolve in organizations. Kassing (1997) argue that some organizational factors, as like structures and practices, define the dissent strategy choices of employees. Organizational justice perception is one of those organizational factors that shapes the employees' dissent behavior (Kassing and McDowell, 2008; Goodboy, Chory and Dunleavy, 2008). Thus, this survey focused on the effects of organizational justice on organizational dissent behaviors.

One of the findings of this survey was the positive effect of procedural justice and distributive justice on dissent behavior. This finding is parallel to research results of Kassing and McDowell (2008), which indicate that justice perceptions of managerial employees increased upward dissent behaviors. Employees with high level of justice perception believe in that they will not be punished for their expressions, so they are more prone to express their contradictory views about the decisions to their executives without any hesitations in a fair organization. On the other hand, the finding of this research implying a nonsignificant effect of interactional justice on organizational justice, is inconsistent with Kassing and McDowell (2008)'s research, which indicates employees getting better relationship with their managers are more prone to upward dissent. In scope of this survey, employees' dissent behaviors are influenced by fairness of formal rules and procedures, and acquisitions rather than the fairness of managerial relationships. This distinctive result of this survey may stem from employees' distrust in relationship with their managers and their prioritization of formal procedures and concrete acquisitions rather than abstract relationships while evaluating the possible retaliations and results of their dissent. Indeed, this findings is noteworthy for a survey conducted in Turkey, such a high power distance culture country, because most of the surveys conducted in Turkey demonstrated that executives are more influential on employees behaviors and attitudes rather than written rules. Moreover, in a huge number of justice related researches, conducted in Turkey, interactional justice was indicated as the most relevant and influential dimension of organizations justice (Yürür, 2015). This incoherent finding of this research can be caused by sample choice. This survey was conducted on employees working in automotive industry, which corporate companies are operating in. In corporate firms, activities are directed through formal decision making process, rules and procedures rather than managers' initiatives. So, employees working at such corporate companies are expected to rely on written procedures and rules rather than managerial relations in their attitudes and behaviors, which may constitute an explanation for the distinctive finding of this research.

Another finding of this survey was the positive significant effect of distributive justice on latent dissent, while negative effects of organizational justice on latent dissent are proposed in this research. According to this survey result, the employees' higher distributive justice perceptions increase their dissent to their co-workers. This positive relationship between distributive justice and latent dissent, which is considered as a mean of resistance to decisions (Kassing and McDowell, 2008), is also striking. When employees perceive outputs of decisions and their acquisitions are fair, their dissent expression to their co-workers increase, which may connote that in a fair climate, employees feel themselves confident and don't hesitate to dissent. That kind of result oriented behavior can be due to the generation characteristics of employees participating in this survey, most of whom belong to Generation Y. Dissent to co-worker in a fair organizational environment can be Generation Y specific behavior.

Because the survey is conducted on a few automotive firms operating in Bursa distinct, findings cannot be generalized, which constitutes the main binding constraint of this study.

\section{Acknowledgments}

This paper was presented at $14^{\text {th }}$ International Strategic Management Conference, which was held between the dates of July 12 14, 2018 in Prague- Czech Republic. 


\section{REFERENCES}

Bies, R. J., Moag, J. F. (1986). Interactional justice: communication criteria of fairness. In R. J. Lewicki, B. H. Sheppard, \& M. H. Bazerman (Eds.), Research on Negotiations in Organizations (Vol. 1, pp. 43-55). Greenwich, CT: JAI Press.

Cohen-Charash, Y., Spector, P. E. (2001). The role of justice in organizations: a meta-analysis. Organizational Behavior and Human Decision Processes, 86, s. 278-321.

Colquitt, J. A. (2001). On the dimensionality of organizational justice: a construct validation of a measure. Journal of Applied Psychology $.86(3) \cdot$.pp.386-400

Colquitt, J. A., LePine, J. A., Piccolo, R. F., Zapata, C. P., Rich, B. L. (2012). Explaining the justice-performance relationship: trust as exchange deepener or trust as uncertainty reducer?. Journal of Applied Psychology, 97: s. 1-15.

Cropanzano, R., Prehar, C. A., Chen, P. Y. (2002). Using social exchange theory to distinguish procedural from interactional justice. Group \& Organization Management, 27, s. $324-351$.

Dağlı, A. (2015). Örgütsel muhalefet ölçeğinin Türkçe'ye uyarlanması: Geçerlik ve güvenirlik çalışması. Elektronik Sosyal Bilimler Dergisi. 14(53). ss.198-218.

Fox, S., Spector, P. E., Miles, D. (2001). Counterproductive Work Behavior (CWB) in response to job stressors and organizational justice: some mediator and moderator tests for autonomy and emotions. Journal of Vocational Behavior, 59, p. 1-19.

Graham, J. W. (1986). Principled organizational dissent: A theoretical essay. Research in Organizational Behavior, 8, 1-52.

Greenberg, J. (1990a). Employee theft as a reaction to underpayment inequity: the hidden cost of paycuts. Journal of Applied Psychology, 75, p. 561-568.

Greenberg, J. (1990a). Organizational justice: yesterday, today, and tomorrow. Journal of Management, 16, 399-432.

Greenberg, J. (1993). The social side of fairness: interpersonal and informational classes of organizational justice. (içinde), Russell CROPANZANO; Justice in the Workplace: Approaching Fairness in Human Resource Management, Lawrence Erlbaum Associates, Publishers, New Jersey.

Goodboy, A. K., Chory, R. M., Dunleavy, K. N. (2008). Organizational dissent as a function of organizational justice. Communication Research Reports, 25, 255-265.

Kassing, J. W. (1997). Articulating, antagonizing, and displacing: A model of employee dissent. Communication Studies, 48, 311-332.

Kassing, W. (1998). Development and validation of the organizational dissent scale. Management Communication Quarterly, Vol. 12, pp. 183229

Kassing, J. W. (2000). Investigating the relationship between superior-subordinate relationship quality and employee dissent. Communication Research Reports, 17, 58-70.

Kassing, J. W. (2011). Dissent in organizations. Cambridge, United Kingdom: Polity Press.

Kassing, J. W., Armstrong, T. A. (2002). Someone 's going to hear about this: examining the association between dissent -Triggering events and employee's dissent expressions. Management Communication Quarterly .16(39),pp.39-65

Kassing, J. W., McDowell, Z. (2008). Talk about fairness: Exploring the relationship between procedural justice and employee dissent. Communication Research Reports, 25, 1-10.

Konovsky, M. A., Pugh, S. D. (1994). Citizenship behavior and social exchange. Academy of Management Journal, 37, p. 656-669.

Lavelle, J. J., Brockner, J., Konovsky, M. A., Price, K. H., Henley, A. B., Taneja, A., Vinekar, V. (2009). Commitment, procedural fairness, and organizational citizenship behavior: a Multifoci analysis. Journal of Organizational Behavior, 30, p. 337-357.

Masterson, S. S., Lewis, K., Goldman, B. M., Taylor, M. S. (2000). Integrating justice and social exchange: the differing effects of fair procedures and treatment on work relationships. Academy of Management Journal, 43, p. 738-748.

Miceli, M. P., Near, J. P., Rehg, M. T., Van Scotter, J. R. (2012). Predicting employee reactions to perceived organizational wrongdoing: demoralization, justice, proactive personality and whistleblowing. Human Relations, 65, p. 923-954.

Moorman, R. H. (1991). Relationship between organizational fairness and organizational citizenship behaviors: do fairness perceptions influence employee citizenship?. Journal of Applied Psychology, 76, p. 845-855.

Pinder, C. C., Harlos, H. P. (2001). Employee silence: quiescence and acquiescence as responses to perceived injustice. Research in Personnel and Human Resource Management, 20, 331-69. 
Rupp, D. E., Cropanzano, R. (2002). The mediating effects of social exchange relationships in predicting workplace outcomes from Multifoci organizational justice. Organizational Behavior and Human Decision Processes, 89, p. 925-946.

Seifert, D. L., Sweeney, J. T., Joireman, J., Thornton, J. M. (2010). The influence of organizational justice on accountant whistleblowing. Accounting, Organizations and Society 35, p. 707-717.

Skarlicki, D. P., Folger, R. (1997). Retaliation in the workplace: the roles of distributive, procedural, and interactional justice. Journal of Applied Psychology, 82, p. 434-443.

Tangirala, S., Ramanujam, R. (2008). Employee silence on critical work issues: The cross level effects of procedural justice climate. Personal Psychology, 61, pp. 37-68.

Yürür, S. (2008). Örgütsel adalet ile iş tatmini ve çalişanlarin bireysel özellikleri arasindaki ilişkilerin analizine yönelik bir araştirma. SDÜ iktisadi ve İdari Bilimler Fakültesi Dergisi, Cilt 13, Sayı 2, s. 295-312.

Yürür, S. (2015). Türkiye'de örgütsel adalet konusunda yapilan çalişmalara ilişkin bir derleme. (içinde) Edt. Kutanis, Türkiye'de Örgütsel Davranış Çalışmaları-I, Gazi Kitabevi, Ankara.

Zapata - Phelan, C. P., Colquitt, J. A., Scott, B. A., Livingston, B. (2009). Procedural justice, interactional justice, and task performance: the mediating role of intrinsic motivation. Organizational Behavior and Human Decision Processes, 108, p. 93-105. 